\title{
RNA-sequencing reveals positional memory of multipotent mesenchymal stromal cells from oral and maxillofacial tissue transcriptomes
}

Satoru Onizuka', Yasuharu Yamazaki ${ }^{2}$, Sung-Joon Park ${ }^{3}$, Takayuki Sugimoto², Yumiko Sone ${ }^{2}$, Sebastian Sjöqvist ${ }^{4}$, Michihiko Usui ', Akira Takeda ${ }^{2}$, Kenta Nakai ${ }^{3}$, Keisuke Nakashima ${ }^{1}$ and Takanori Iwata ${ }^{4,5^{*}}$

\begin{abstract}
Background: Multipotent mesenchymal stromal cells (MSCs) can be isolated from numerous tissues and are attractive candidates for therapeutic clinical applications due to their immunomodulatory and pro-regenerative capacity. Although the minimum criteria for defining MSCs have been defined, their characteristics are known to vary depending on their tissue of origin.

Results: We isolated and characterized human MSCs from three different bones (ilium (I-MSCs), maxilla (Mx-MSCs) and mandible (Md-MSCs)) and proceeded with next generation RNA-sequencing. Furthermore, to investigate the gene expression profiles among other cell types, we obtained RNA-seq data of human embryonic stem cells (ESCs) and several types of MSCs (periodontal ligament-derived MSCs, bone marrow-derived MSCs, and ESCs-derived MSCs) from the Sequence Reads Archive and analyzed the transcriptome profile. We found that MSCs derived from tissues of the maxillofacial region, such as the jaw bone and periodontal ligament, were HOX-negative, while those derived from other tissues were HOX-positive. We also identified that MSX1, LHX8, and BARX1, an essential regulator of craniofacial development, were strongly expressed in maxillofacial tissue-derived MSCs. Although MSCs may be divided into two distinct groups, the cells originated from over the neck or not, on the basis of differences in gene expression profile, the expression patterns of all CD antigen genes were similar among different type of MSCs, except for ESCs.
\end{abstract}

\footnotetext{
* Correspondence: iwata.peri@tmd.ac.jp

${ }^{4}$ Institute of Advanced Biomedical Engineering and Science, Tokyo Women's

Medical University, 8-1 Kawada-cho, Shinjuku-ku, Tokyo 162-8666, Japan

${ }^{5}$ Department of Periodontology, Graduate School of Medical and Dental

Sciences, Tokyo Medical and Dental University, 1-5-45 Yushima, Bunkyo-ku,

Tokyo 113-8510, Japan

Full list of author information is available at the end of the article
}

(c) The Author(s). 2020, corrected publication 2020. Open Access This article is licensed under a Creative Commons Attribution 4.0 International License, which permits use, sharing, adaptation, distribution and reproduction in any medium or format, as long as you give appropriate credit to the original author(s) and the source, provide a link to the Creative Commons licence, and indicate if changes were made. The images or other third party material in this article are included in the article's Creative Commons licence, unless indicated otherwise in a credit line to the material. If material is not included in the article's Creative Commons licence and your intended use is not permitted by statutory regulation or exceeds the permitted use, you will need to obtain permission directly from the copyright holder. To view a copy of this licence, visit http://creativecommons.org/ licenses/by/4.0/. The Creative Commons Public Domain Dedication waiver (http://creativecommons.org/publicdomain/zero/1. 0/) applies to the data made available in this article, unless otherwise stated in a credit line to the data. 


\begin{abstract}
(Continued from previous page)
Conclusions: Our findings suggest that MSCs from different anatomical locations, despite meeting general characterization criteria, have remarkable differences in gene expression and positional memory. Although stromal cells from different anatomical sources are generally categorized as MSCs, their differentiation potential and biological functions vary. We suggested that MSCs may retain an original tissue memory about the developmental process, including gene expression profiles. This could have an important impact when choosing an appropriate cell source for regenerative therapy using MSCs.
\end{abstract}

Keywords: Multipotent mesenchymal stromal cells, RNA-sequencing, HOX genes, Maxillofacial bone, lliac bone, Periodontal ligament

\section{Background}

Multipotent mesenchymal stromal cells (MSCs) are capable of clonogenic proliferation and differentiation into all mesodermal lineages [1]. They can be isolated from several tissues, such as bone marrow [2], adipose tissue [3], periosteum [4], and periodontal ligaments [5, 6], and have been used therapeutically for tissue regeneration and autoimmune disease treatment because of their multipotency, immunomodulatory properties, and ability to mediate trophic factors [7]. Researchers have also suggested that cells originating from bone tissue, for instance, femurs, iliac, and alveolar bone, possess MSClike characteristics [8-10].

In the case of bone grafting, progenitor cells that can differentiate into osteoblasts exist in bone tissue and are used in autologous bone grafting for the reconstruction of bony defects. Although several biomaterials have recently attracted attention for their use in bone regeneration [11], the gold standard of clinical bone repair strategies remains the transplantation of autologous bone grafts. Autogenous iliac bone grafting is usually performed to close the bony defects at the alveolar cleft [12]. The iliac bone is the most common donor site for autologous bone grafts because of the availability of sufficient bone and easy access to cancellous bone [13]. Moreover, since autogenous iliac bone is harvested from the patient, it is considered nonimmunogenic and histocompatible. Autogenous iliac bone grafting is generally applied before eruption of the permanent canines, which offers the advantages of stabilization of the maxillary dental arch, creation of bony support for teeth adjacent to the alveolar cleft, closure of the oronasal fistulas, and enhancement of orthodontic and prosthetic treatment $[14,15]$.

However, the harvesting of autogenous bone grafts is associated with risks of donor site morbidity, such as postoperative pain, altered sensation, donor site infection, and scarring [16]. To avoid this, new strategies for bone regenerative therapy have been investigated, including bioresorbable scaffolds, growth factors such as bone morphogenetic proteins and fibroblast growth factor, and gene therapy [17-20]. Additionally, stem cell transplantation is a promising alternative to autologous bone grafting, and a combination of cultured MSCs and biomaterials was shown to be effective in various animal models for repairing bony defects [21-23]. However, it remains unclear which source of MSCs is the most suitable for bone regeneration.

The maxillofacial skeleton is derived from the cranial neural crest whereas the remainder of the skeleton originates from the mesoderm [24, 25]. It is therefore fundamental to determine whether progenitor cells originating from bone tissue derived from mesoderm can completely regenerate or repair maxillofacial bone. Although MSCs derived from various tissue satisfy the international minimal defining criteria, these cells exhibit different characteristics in terms of proliferation ability, differentiation potential, and gene expression profiles [26-28]. Therefore, to investigate variations in differentiation abilities and gene expression patterns among various types of MSCs, we performed differentiation assay and RNA-sequencing (RNA-seq) using next-generation sequencing analysis. Our results suggest that MSCs derived from different types of tissue, especially the cells originated from over the neck or not, have positional memories and varying gene expression profiles that may influence their cellular characteristics.

\section{Results \\ MSCs from different anatomical locations exhibit varying differentiation potential}

First, to verify that the cells used in this study have multipotency to differentiate into several cell types, we performed differentiation assays (Fig. 1 and Figure S1). Alizarin red S staining showed that all types of MSCs could differentiate into osteoblasts and form mineralized nodules, but the degree of mineralization was lower for maxilla-derived MSCs (Mx-MSCs) than for other MSCs (Fig. 1a). Oil Red $\mathrm{O}$ and toluidine blue staining assay showed that ilium-derived MSCs (I-MSCs) had the greatest potential for adipogenic and chondrogenic differentiation compared with Mx-MSCs and mandible- 
A

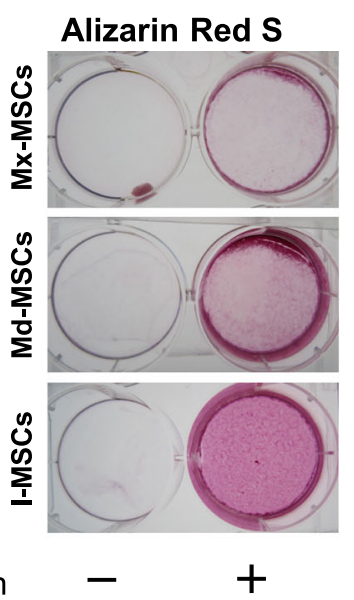

C
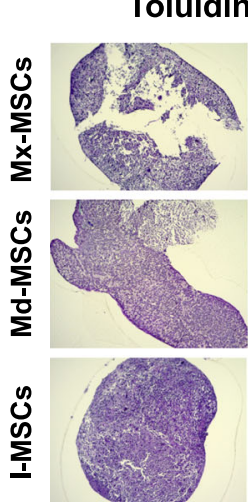

Induction
B

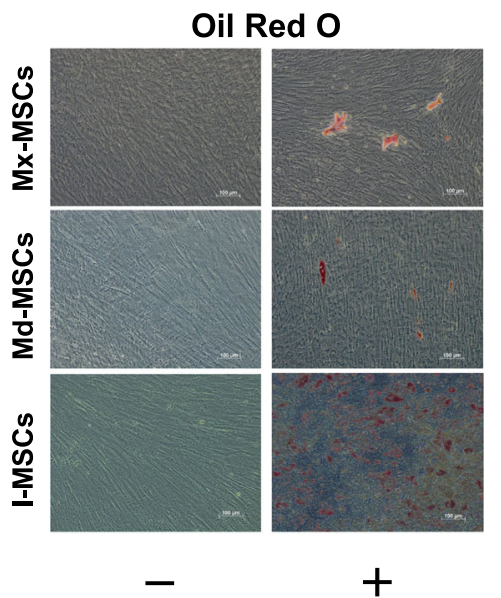

D

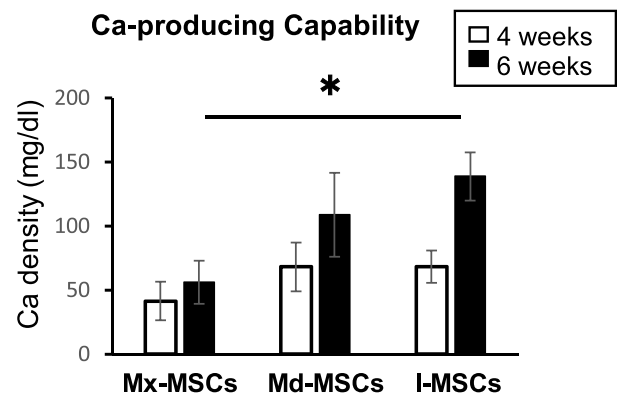

Fig. 1 Differentiation potential of each type of bone-derived MSCs. a Alizarin red S staining of MSCs cultured in ODM or complete medium for 6 weeks. -, MSCs cultured in complete medium for 6 weeks; +, MSCs cultured in ODM for 6 weeks. b Oil red O staining of MSCs cultured in ADM or ODM for 6 weeks. -, MSCs cultured in ODM for 6 weeks; +, MSCs cultured in ODM for 3 weeks, then in ADM for 3 weeks. c Toluidine blue staining of MSCs cultured in CDM or complete medium for 3 weeks. -, MSCs cultured in complete medium for 3 weeks; +, MSCs cultured in ODM for 3 weeks. These images show the representative data from three different samples; a similar tendency was observed in other MSCs. $d$ Calcium was produced when MSCs were cultured in ODM for 4 and 6 weeks. Bars represent the mean \pm S.D. of triplicate samples. Asterisks denote significant difference $(p<0.05$, Tukey's HSD)

derived MSCs (Md-MSCs) (Fig. 1b and c). In the calcium content assay, I-MSCs and Md-MSCs produced more Ca than Mx-MSCs when the cells were cultured in ODM for 4 weeks (Fig. 1d). Moreover, Ca levels in IMSCs were significantly higher than in Mx-MSCs when the cells were cultured in ODM for 6 weeks (Fig. 1d).

\section{The general profile of RNA-seq data}

The Ion Proton system generated 31.5-52.8 million single-ended $50-200 \mathrm{bp}$ reads from nine samples (Fig. 2a). Unmapped reads were reduced to less than 5\% by removing low-quality reads. Genes with low expression (fragments per kilobase of exon per million mapped fragments $($ FPKM $)<1.0)$ were removed from the three groups, leaving a total of 12,676 genes. Most non-coding RNAs (long intergenic noncoding RNAs, microRNAs, small nuclear RNAs, small nucleolar RNAs, and pseudogenes) had a FPKM $<1$ in all samples (Fig. $2 b$ ). To verify that the cells used in this study have specific MSC markers, we analyzed the gene expression profile of CD14, CD45 (PTPRC), CD73 (NT5E), CD90 (THY1), and CD105 (ENG). RNA-seq data of human macrophage (MФ) used as control ware obtained from the Sequence Reads Archive (DDBJ accession number: SRA245718). In three types of MSCs, the expression levels of CD73, CD90, and CD105, widely known as specific surface markers of MSCs, were higher than those in MФ. On the other hand, the three types of MSCs had little 
B

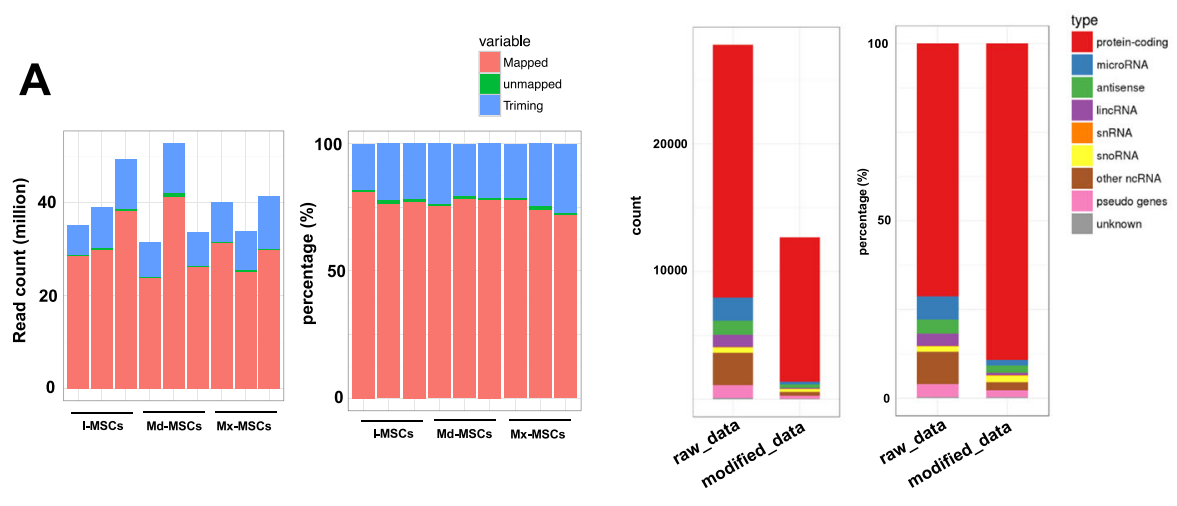

C

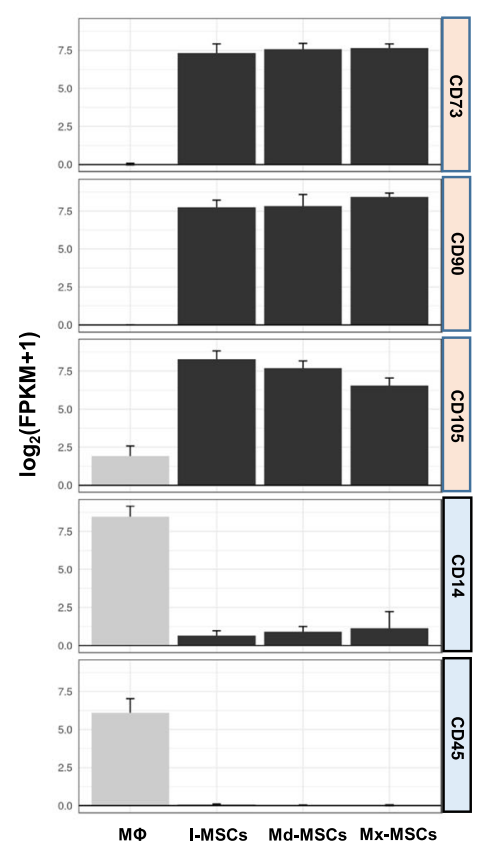

D

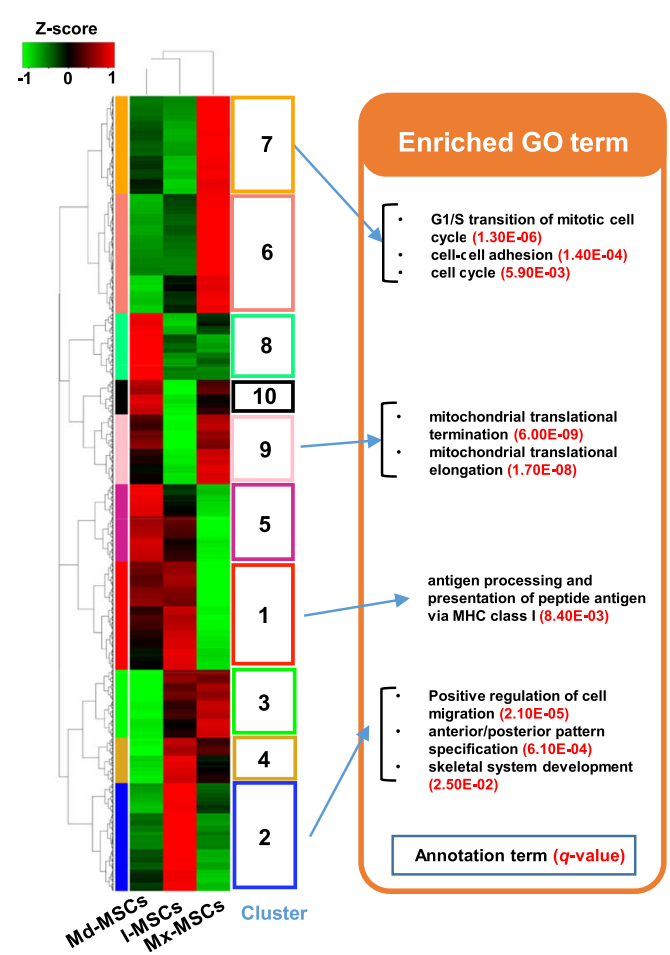

Fig. 2 Gene expression profile and GO term enrichment analysis of bone-derived MSCs. a Cumulative number (left) and ratio (right) of singleended reads generated from the Ion Proton system $(1$ e $07=10,000,000)$. $\mathbf{b}$ Cumulative number (left) and ratio (right) of sequencing reads aligned to the human reference genome (hg19). Each color represents a different RNA biotype, such as protein-coding RNA, non-coding RNA, and unknown. 'modified_data' is Refseq genes expressed in at least one group with FPKM $\geq 1$. c The expression levels of CD14, CD45, CD73, CD90, and CD105 among each type of cells. The RNA-seq data (accession number: SRA245718) of human Macrophage (MФ) were used as control. d Heatmap showing the relative expression profile of 12,676 genes (FPKM $\geq 1$ ) among I-MSCs, Mx-MSCs, and Md-MSCs. Scaled expression values are color-coded according to the legend on the left. These genes were categorized into 10 patterns by a hierarchical clustering approach. The genes in each pattern were over-represented by specific GO biological process terms $(q<0.05)$

expression of CD14 and 45 (Fig. 2c). Using genes expressed in at least one of the groups with FPKM $\geq 1$, we detected 10 different gene clusters in MSCs that exhibited distinct expression patterns (Fig. 2d). The genes in each cluster were significantly enriched by specific GO terms. For instance, GO terms associated with the cell cycle and cell adhesion detected from cluster 7 consisted of genes up-regulated in $\mathrm{Mx}$ MSCs compared with other MSCs, while GO terms associated with cell migration detected from cluster 2 consisted of genes up-regulated in I-MSCs compared with other MSCs. These results suggested that the cell growth and migration properties of each cell type were different. 
GO term enrichment analysis reveals differences between I-MSCs and Mx-/Md-MSCs

To detect potential key regulators of each sample, we investigated DEGs between Mx-MSCs vs. I-MSCs, MdMSCs vs. I-MSCs, and Mx-MSCs vs. Md-MSCs, and identified 973, 365, and 602 DEGs, respectively (Fig. 3a). To investigate differences in skeletal development and endochondral and intramembranous ossification, GO term enrichment analysis for I-MSC-specific DEGs was performed. A total of 140 DEGs were up-regulated in IMSCs compared with Mx- and Md-MSCs (U-DEGs) (Fig. 3b). DAVID annotation of these DEGs revealed that most of the top 10 enriched GO terms were involved in development. A total of 96 DEGs were down-regulated

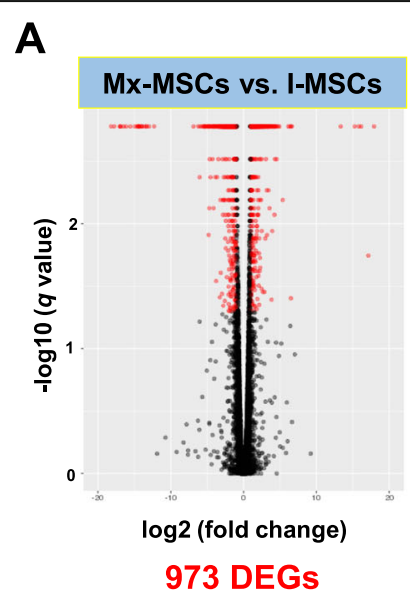

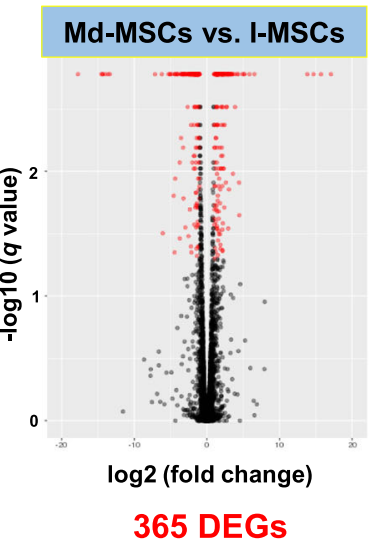

365 DEGs
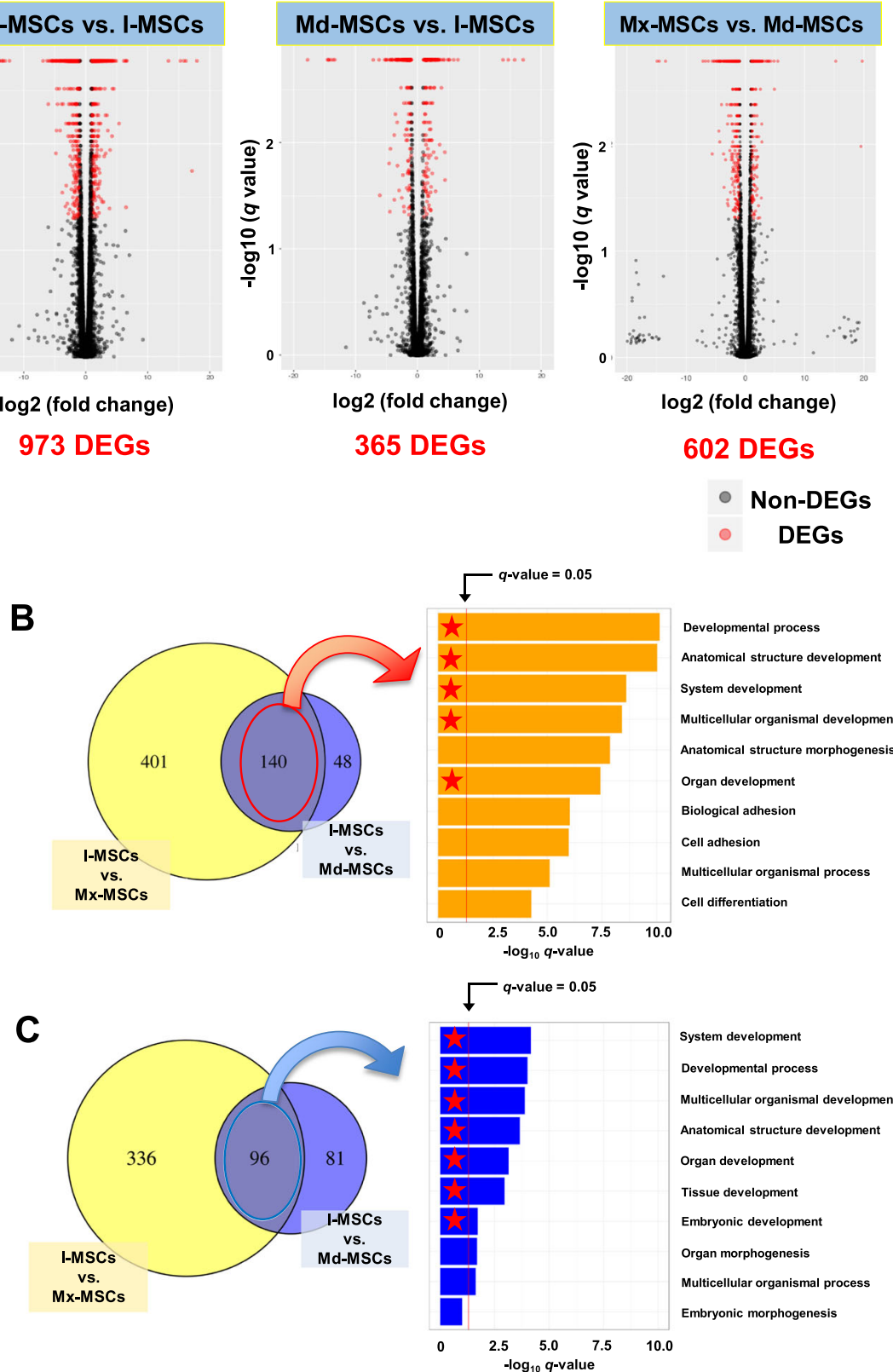

Fig. 3 Profile of specific differentially expressed genes (DEGs) and GO term enrichment analysis using the DEGs. a Volcano plot showing all profiled genes. Gray and red circles represent non-DEGs and DEGs, respectively. Statistical analysis detected DEGs between two samples using a threshold ( $q$-value $<0.05$ and a more than two-fold change in FPKM). b, c High (b) and low (c) expressed DEGs in I-MSCs compared with Mx / Md-MSCs. Venn diagram shows the number of DEGs in I-MSCs vs. Mx-MSCs (yellow circle) and I-MSCs vs. Md-MSCs (blue circle). Bar plot shows the top 10 enriched GO terms identified from co-DEGs (mid area in the Venn diagram) using statistical analysis (horizontal axis represents $\log _{10}[q$-value]). Red stars indicate the GO term involved in development 
in I-MSCs compared with Mx- and Md-MSCs (DDEGs), and most of the top 10 enriched GO terms were also involved in development (Fig. 3c). These results indicate that I-MSCs and $\mathrm{Mx}-/ \mathrm{Md}-\mathrm{MSCs}$ are regulated by genes involved in development.

\section{Whole transcriptome analysis shows that MSCs derived} from tissue in the maxillofacial region are HOX-negative Based on GO term analysis, significant DEGs between IMSCs and MSCs derived from jaw bone $(\mathrm{Mx}-/ \mathrm{Md}-$ MSCs) were selected in order of the largest fold change. The top 20 up-regulated DEGs in I-MSCs compared with Mx- or Md-MSCs revealed that most genes specifically expressed in I-MSCs were from the HOX gene family although WISP3 was also specifically expressed in I-MSCs (Tables 1 and 2).

Next, we further evaluated the expression profile of all HOX genes among the three samples. We obtained HOX FPKM values, and analyzed the degree and distribution of HOX gene expression levels (Figures S2A and S2B). I-MSCs were found to have a HOX-positive profile, while MSCs derived from jaw bones $(\mathrm{Mx}-/ \mathrm{Md}-$ MSCs) had HOX-negative profiles. To investigate the gene expression profiles of other cell types, we obtained

Table 1 The top 20 up-regulated DEGs in I-MSCs compared with Mx-MSCs

\begin{tabular}{|c|c|c|c|}
\hline & \multicolumn{2}{|c|}{ FPKM (Mean) } & \multirow{2}{*}{$\begin{array}{l}\mathrm{FC} \\
(\log 2)\end{array}$} \\
\hline & I-MSCS & Mx-MSCs. & \\
\hline $\mathrm{HOXC6}^{\mathrm{a}}$ & 30.353 & $<0.0001$ & $\overline{18.211}$ \\
\hline $\mathrm{HOXC10^{a }}$ & 22.068 & $<0.0001$ & 17.752 \\
\hline $\mathrm{HOXC8}{ }^{a}$ & 12.962 & $<0.0001$ & 16.984 \\
\hline HOXB4 ${ }^{a}$ & 12.954 & $<0.0001$ & 16.983 \\
\hline HOXC9 ${ }^{a}$ & 12.075 & $<0.0001$ & 16.882 \\
\hline HOXA3 ${ }^{a}$ & 1.255 & $<0.0001$ & 16.487 \\
\hline HOXA11 ${ }^{a}$ & 2.189 & $<0.0001$ & 14.912 \\
\hline HOXD4 ${ }^{\mathrm{a}}$ & 2.538 & $<0.0001$ & 14.631 \\
\hline HOXA5 ${ }^{a}$ & 3.083 & $<0.0001$ & 14.528 \\
\hline HOXA7 ${ }^{a}$ & 7.18 & $<0.0001$ & 14.347 \\
\hline HOXA4 ${ }^{a}$ & 2.084 & $<0.0001$ & 14.345 \\
\hline HOXC-AS1 ${ }^{a, b}$ & 2.071 & $<0.0001$ & 14.338 \\
\hline HOXC-AS2 a,b & 1.64 & $<0.0001$ & 14.001 \\
\hline $\mathrm{HOXC11^{a }}$ & 1.627 & $<0.0001$ & 13.99 \\
\hline HLA-DQB1 & 0.81 & $<0.0001$ & 13.982 \\
\hline HOXA6 ${ }^{a}$ & 4.767 & $<0.0001$ & 13.616 \\
\hline HOXA-AS2 $2^{a, b}$ & 2.081 & $<0.0001$ & 13.366 \\
\hline WISP3 & 1.056 & $<0.0001$ & 13.331 \\
\hline HOXA1 ${ }^{a}$ & 2.363 & $<0.0001$ & 12.984 \\
\hline HOTAIRM1 ${ }^{a, b}$ & 9.188 & $<0.0001$ & 12.278 \\
\hline
\end{tabular}

a HOX gene family, ${ }^{b}$ non-coding RNAs, FC: Fold change of FPKM value between two samples (log2 of FC)
Table 2 The top 20 up-regulated DEGs in I-MSCs compared with Md-MSCs

\begin{tabular}{|c|c|c|c|}
\hline & \multicolumn{2}{|c|}{ FPKM (Mean) } & \multirow{2}{*}{$\begin{array}{l}\mathrm{FC} \\
(\log 2)\end{array}$} \\
\hline & I-MSCS & $\overline{M d-M S C s}$ & \\
\hline VTRNA1-1 ${ }^{\mathrm{b}}$ & 336.731 & $<0.0001$ & 21.693 \\
\hline $\mathrm{HOXC10}{ }^{a}$ & 22.068 & $<0.0001$ & 17.752 \\
\hline HOXA1 a & 2.363 & $<0.0001$ & 14.528 \\
\hline HOXA4 ${ }^{\text {a }}$ & 2.084 & $<0.0001$ & 14.347 \\
\hline HOXA-AS2 a,b & 2.081 & $<0.0001$ & 14.345 \\
\hline HOXC-AS2 a,b & 1.64 & $<0.0001$ & 14.001 \\
\hline HOXA3 ${ }^{a}$ & 1.255 & $<0.0001$ & 13.616 \\
\hline WISP3 & 1.056 & $<0.0001$ & 13.366 \\
\hline $\mathrm{HOXC6}^{\mathrm{a}}$ & 30.353 & 0.214447 & 7.145 \\
\hline CACNG8 & 10.729 & 0.145148 & 6.208 \\
\hline $\mathrm{HOXC9}{ }^{\mathrm{a}}$ & 12.075 & 0.179618 & 6.071 \\
\hline LOC400043 b & 11.018 & 0.28332 & 5.281 \\
\hline CELSR3 & 7.617 & 0.223098 & 5.093 \\
\hline $\mathrm{HOXB7^{a }}$ & 16.183 & 0.494379 & 5.033 \\
\hline CHI3L1 & 18.989 & 0.660538 & 4.845 \\
\hline ROR2 & 1.729 & 0.0724027 & 4.577 \\
\hline $\mathrm{HIST} 1 \mathrm{H} 2 \mathrm{BH}$ & 13.291 & 0.606649 & 4.454 \\
\hline UNC5C & 1.071 & 0.0503351 & 4.412 \\
\hline TENM2 & 1.548 & 0.0745513 & 4.376 \\
\hline HOXA11 ${ }^{a}$ & 2.189 & 0.106172 & 4.366 \\
\hline
\end{tabular}

${ }^{\mathrm{a}} \mathrm{HOX}$ gene family, ${ }^{\mathrm{b}}$ non-coding RNAs, FC: Fold change of FPKM value between two samples (log2 of FC)

RNA-seq data from human embryonic stem cells (ESCs), human ESC-derived MSCs (ES-MSCs), and human bone marrow-derived MSCs (BM-MSCs) from the Sequence Reads Archive (DDBJ accession number: SRA245478) and previous RNA-seq data owned by Tokyo Women's Medical University (TWMU) from human periodontal ligament-derived MSCs (PDL-MSCs), BM-MSCs (TWMU-BMMSCs), and BM-MSCs cultured in ODM (ODMSCs). Figure 4a and b show that ECSs and PDLMSCs also possessed a HOX-negative profile, similar to Mx- and Md-MSCs. Interestingly, although ESCs had a HOX-negative profile, the expression patterns of HOX genes changed to HOX-positive after the cells differentiated into MSCs. There was less change in the expression profile of HOX genes between TWMU-BMMSCs and ODMSCs, suggesting that HOX mRNA expression may not be affected by ODM.

\section{Characteristics of gene expression patterns in different types of tissue-derived MSCs and ESCs}

To investigate whether HOX-negative MSCs such as PDL-MSCs, Mx-MSCs, and Md-MSCs showed similar gene expression patterns, U-DEG and D-DEG mRNA expression was analyzed among nine samples. U-DEG 
A

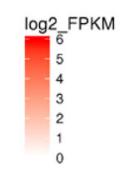

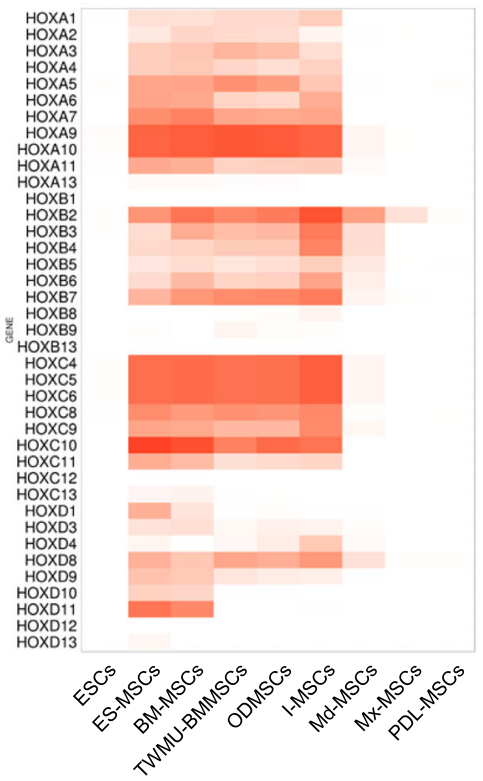

B

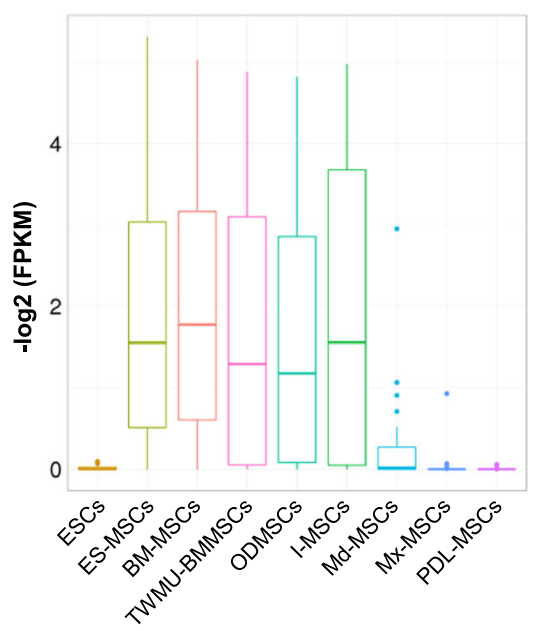

Fig. 4 Gene expression profile of all HOX genes among MSCs and ESCs. a Heat map showing the degree of expression levels (Iog2 of FPKM value) of all HOX genes. $\mathbf{b}$ Box plot showing the distribution of expression levels (log2 of FPKM value) of HOX genes (except HOX genes with FPKM $=0$ in all samples). ESCs, human embryonic stem cells; ES-MSCs, human ESC-derived MSCs; BM-MSCs, human bone marrow-derived MSCs; TWMU-BMMSCs, BM-MSCs owned by TWMU; ODMSCs, TWMU-BMMSCs cultured with ODM; PDL-MSCs, periodontal ligament-derived MSCS

and D-DEG expression patterns in PDL-MSCs were similar to those in $\mathrm{Mx}-/ \mathrm{Md}-\mathrm{MSCs}$, while $\mathrm{U}-\mathrm{DEG}$ and D-DEG expression patterns in MSCs derived from bone marrow (BM-MSCs, TWMU-BMMSCs, and ODMSCs) and ES-MSCs were similar to those in I-MSCs (Figures $\mathrm{S} 3 \mathrm{~A}$ and $\mathrm{S} 3 \mathrm{~B})$. These results revealed the similarity of HOX-negative MSCs and the similarity of HOX-positive MSCs with respect to gene expression profiles in UDEGs and D-DEGs.

Next, we investigated the specific up-regulated DEGs in maxillofacial region-derived MSCs (Mx-MSCs, MdMSCs, and PDL-MSCs; Mfr-MSCs) compared with the others. We identified 8 genes with FPKM levels in each Mfr-MSC sample that were twice as high as in the other six samples: MSX1, NCAM1, LHX8, BARX1, FOXF1, S100A4, ZNF185, and NPTX1 (Fig. 5). The expression levels of $L H X 8, B A R X 1, F O X F 1$, and NCAM1 were quite low $(\mathrm{FPKM}<1.0)$ in non Mfr-MSCs, indicating that they could be used as specific marker genes for Mfr-MSCs.

\section{Gene expression profiles of $C D$ antigens in each sample}

Fig. 6 shows the gene expression profile of $\mathrm{CD}$ molecules in each type of MSC and ESC. The mRNA expression of positive markers for MSCs, such as CD105, CD73, and CD44, was significantly higher (FPKM > 50) in all MSCs compared with ESCs (FPKM <3.0). CD90, an MSCpositive marker, was highly expressed (FPKM >100) in both MSCs and ESCs. The mRNA expression of MSCnegative markers, such as CD14, CD34, and CD45, showed low levels (FPKM <2.0) in MSCs and ESCs. CD106 and CD270 were not expressed (FPKM =0) in ESCs, although these genes demonstrated high or low expression in MSCs. The expression patterns of all CD antigen genes were similar among different type of MSCs, except for ESCs.

\section{Discussion}

Although several studies have suggested that MSCs can be isolated from various tissues, such cells have different in vitro characteristics such as proliferation abilities, differentiation potentials, and gene expression profiles [26, 27]. In the present study, I-MSCs readily differentiated into both osteoblasts and adipocytes; in contrast, $\mathrm{Mx}$ MSCs and Md-MSCs, derived from bone of the maxillofacial region, hardly differentiated into adipocytes, and the osteogenic potential of Mx-MSCs was significantly lower than that of I-MSCs.

In support of this, alveolar BM-MSCs were previously found to show little differentiation into adipocytes and chondrocytes, in contrast to ilium BM-MSCs [29]. However, the differentiation potential and HOX genes profile of maxilla differ from those of the mandible, which may reflect the fact that Md-MSCs were isolated from bone tissue of the mandibular angle. Although the 

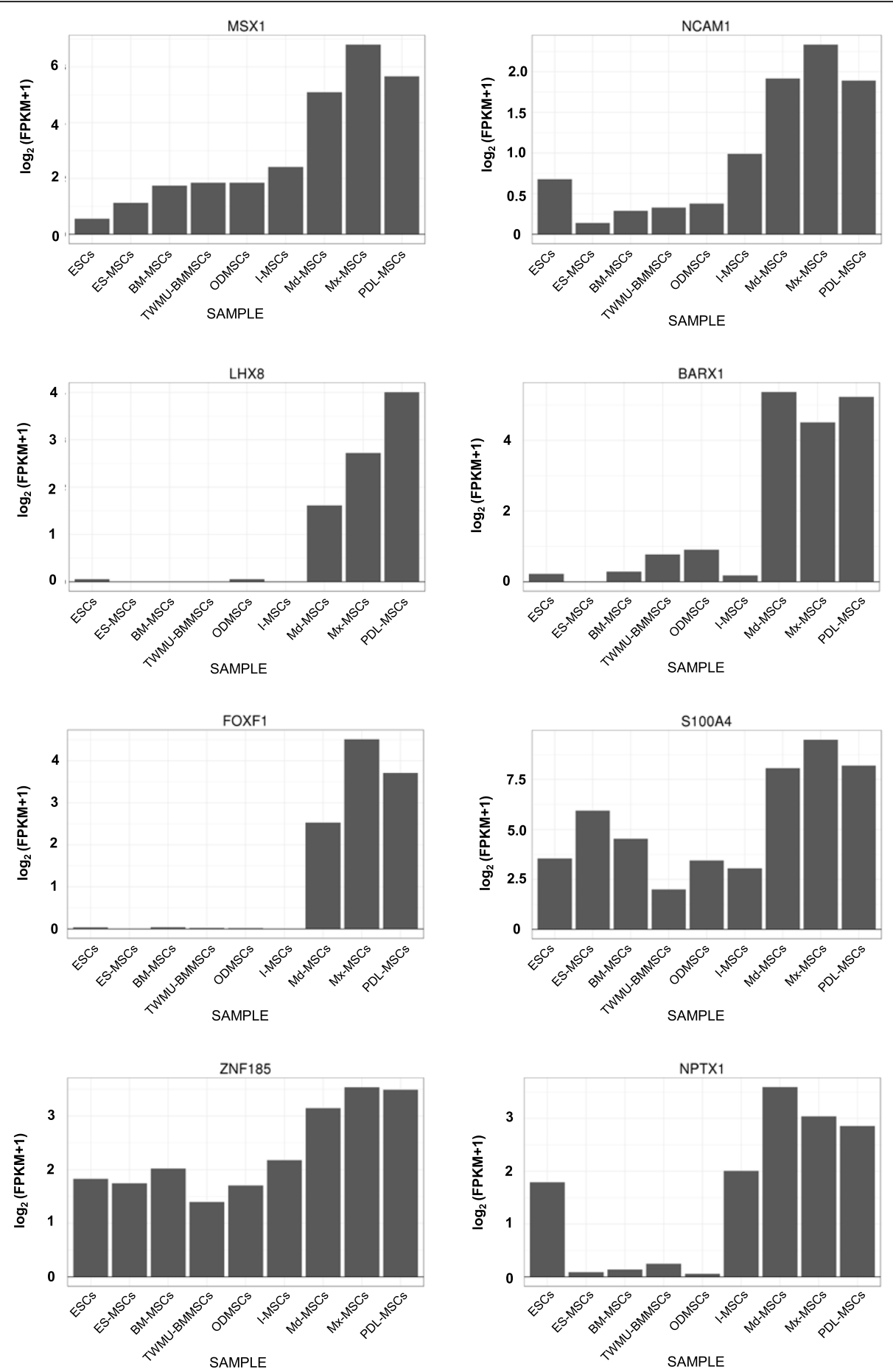

Fig. 5 Specific up-regulated DEGs in oral and maxillofacial tissue-derived MSCs. The vertical axis represents gene expression levels with log2 of $[\mathrm{FPKM}+1]$

maxillofacial bone is usually formed by intramembranous ossification [30,31], the condyle, coronoid, and angular of the mandible develop through endochondral ossification [32]. Therefore, cells in the mandibular angle have different characteristics to those in the maxilla even though they are both maxillofacial bone. RNA-seq findings of our study also showed a difference in gene expression profiles between Mx-MSCs and Md-MSCs, which should be studied further.

We focused our attention on gene expression profile among MSCs derived from maxillofacial bone of neural crest origin and iliac bone of mesoderm origin in RNA- 


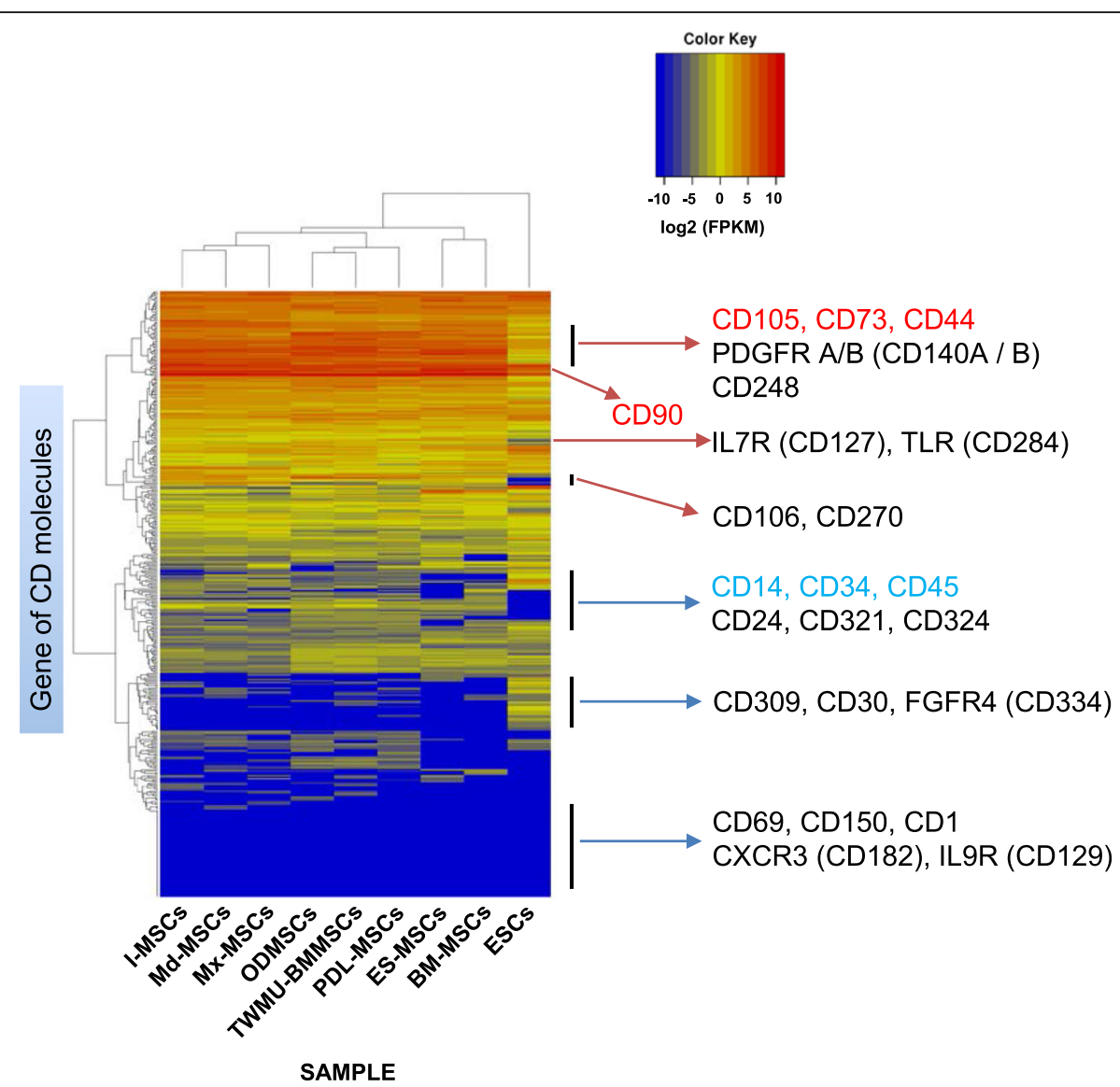

Fig. 6 Gene expression profile of CD molecules in each sample. Heatmap showing the degree of expression levels (log2 of FPKM value) of all CD genes. Scaled expression values are color-coded according to the legend on the left. Genes are hierarchically clustered by the similarity of their expression profiles over the set of samples, and the samples are hierarchically clustered by the similarity of expression patterns over their expression profile. The described genes (right side of heatmap) are representative CD molecules. Red letters represent positive markers for MSCs, and blue letters represent negative markers for MSCs

seq data analysis. While these cells generally are classified as MSCs, the gene expression profiles, particularly the HOX gene family are greatly different. MSCs originating from the ilium were shown to be HOX-positive, while those originating from the maxillofacial bone were HOX-negative. This study had a limitation in that distribution of donor age among each type of MSCs was uneven. Since primary culture was performed using remaining bone tissue obtained from bone grafting in cleft lip and palate patients or osteotomy in jaw deformity patients, donor age was dependent on operation timing. However, our previous study showed that ALP activity of I-MSCs cultured in osteoinductive medium for 1 week was not different from that of Md-MSCs [33]. Therefore, it is quite likely that HOX genes profile of MSCs is not related to donor age. Furthermore, PDLMSCs residing in the maxillofacial region were also HOX-negative. Interestingly, some researchers have suggested that human fibroblasts retain the memory of the embryonic HOX status both in vitro and in vivo [34,
35]. Therefore, MSCs may retain memory from the developmental process, whether the cells derived from neural crest or not.

Our findings are consistent with previous studies, which showed that the Hox status of tibiae was positive, while that of the mandibular was negative [28, 36]. Moreover, Matsubara et al. showed that alveolar bone marrow-derived MSCs hardly differentiated into chondrocytes compared with iliac bone marrow-derived MSCs [29], while Iwata et al. found that the chondrogenic differentiation capacity of PDL-MSCs was lower than that of adipose-derived or bone marrow-derived MSCs [37]. Thus, HOX-negative MSCs might be less prone to differentiate into chondrocytes compared with HOX-positive MSCs. Because the progenitor of HOXnegative maxillofacial bone typically forms bone via intramembranous ossification and does not follow the differentiation process into chondrocytes, it is assumed that MSCs originating from the same region may be programmed not to differentiate into chondrocytes. 
However, our RNA-seq data showed that several HOX genes were expressed in Md-MSCs, which therefore may not be completely HOX-negative despite the fact that the cells originated from maxillofacial bone. The cause of this discrepancy may reflect the characteristics of $\mathrm{Md}$ MSCs isolated from the mandibular angle which develop through endochondral ossification. The results also suggest that the HOX gene cluster regulates the chondrogenic differentiation of MSCs.

Our RNA-seq data revealed that Mfr-MSCs were HOX-negative, and identified specifically up-regulated genes in Mfr-MSCs, including MSX1, NCAM1, LHX8, BARX1, FOXF1, S100A4, ZNF185, and NPTX1. A previous study identified severe craniofacial defects in $M s \times 1^{-/-}$mice including the failure of palatal shelves to elevate and fuse, mandible and middle ear ossicle deformities, the absence of molars, and delayed ossification $[38,39]$. Other research indicated that mutations in human MSX1 are associated with cleft palate and tooth agenesis [40,41]. Additionally, a targeted $L h x 8$ mutation in mice caused cleft palate in around $60 \%$ of animals [42]. Moreover, the microdeletion of BARX1 in humans is associated with craniofacial developmental disorders such as microstomia and mandibular retrusion [43], while BARX1 was recently shown to function as a direct downstream factor of GATA4 in neural crest development [44]. Hence, the Mfr-MSC-specific up-regulated genes obtained from our RNA-seq data may serve as key factors for neural crest or craniofacial bone (intramembranous ossification) development. In contrast, previous studies found that the ectopic expression of several Hox genes induced craniofacial and skeletal malformation in transgenic mice $[45,46]$. Therefore, some Hox genes appear not to be expressed in the cranial region during development. These findings suggest that the maxillofacial region is regulated by different transcription factors to other regions during development, and it is inferred from our RNA-seq data that MSCs inherit site-specific memories.

The International Society for Cellular Therapy (ISCT) proposed sets of minimum criteria to identify MSCs [47]. In fact, our RNA-seq data revealed similar expression patterns of specific cell surface marker genes among each type of MSCs, except for ESCs. Moreover, despite differences in the differentiation capacity among MSC types, these cells nevertheless possessed a multilineage differentiation ability. Therefore, although cells that fulfill the minimum ISCT criteria are categorized as the same MSCs, it may be more effective to use MSCs derived from the same tissue for cell therapy considering that they inherit the characteristics of the tissue of origin. Indeed, adipose-derived MSCs possessed a high potential for adipogenesis [48], while cartilage-derived MSCs had a high potential for chondrogenesis in an in vitro assay [49]. In in vivo studies, PDL-MSCs showed the greatest potential to regenerate periodontal ligament tissue compared with other sources of MSCs [50]. Considering the varied characteristics of MSCs, it is important to carefully consider the most suitable source for the regeneration therapy of target tissue.

\section{Conclusions}

In this study, Mx / Md-MSCs were shown to have a different gene expression profile compared to I-MSCs, based on RNA-sequencing. In particular, since HOX status of MSCs originating from oral and maxillofacial tissues was HOX-negative, the expression patterns of HOX genes are quite different whether the cells derived from over the neck or not. Although stromal cells from different anatomical sources are generally categorized as MSCs, their differentiation potential and biological functions vary. Our findings suggest that MSCs may retain an original tissue memory about the developmental process, including gene expression profiles. This could have an important impact when choosing an appropriate cell source for regenerative therapy using MSCs.

\section{Methods}

\section{Specimens and cell cultures}

Nine bone specimens (ilium: three cases, maxilla: three cases, mandible: three cases; Table S1) were harvested from conventional surgery conducted by the Department of Plastic and Aesthetic Surgery at Kitasato University. Table S1 shows patient profiles, including sex, age, and type of bone. Small pieces of bone were cultured in complete medium containing $10 \%$ fetal bovine serum (MP Biomedicals LLC, Santa Ana, CA) at $37^{\circ} \mathrm{C}$ with 95\% humidity and $5 \% \mathrm{CO}_{2}$. The complete medium consisted of alpha-minimum essential medium (Thermo Fisher Scientific, Waltham, MA) with $100 \mathrm{U} / \mathrm{mL}$ penicillin, $100 \mu \mathrm{g} / \mathrm{mL}$ streptomycin (Thermo Fisher Scientific), and $1 \mathrm{ng} / \mathrm{mL}$ basic fibroblast growth factor (R\&D Systems, Minneapolis, MN). The medium was changed twice a week during expansion culture. All experiments were conducted with MSCs from second and third passages in this study.

\section{Differentiation for osteogenesis and adipogenesis}

MSCs were cultured in complete medium at confluence, and then seeded in 6-well plates at a density of $1 \times 10^{5}$ cells/well. For osteogenic differentiation, the cells were induced by culturing in osteogenic differentiation medium (ODM), consisting of complete medium supplemented with $50 \mu \mathrm{M}$ ascorbic acid (Wako Pure Chemical Industries, Osaka, Japan), $10 \mathrm{mM} \quad \beta$ glycerophosphate (Calbiochem, San Diego, CA), and $100 \mathrm{nM}$ dexamethasone (Sigma-Aldrich, St Louis, MO). The medium was replaced twice a week. 
For adipogenic differentiation, the cells were induced by culturing in adipogenic differentiation medium (ADM), consisting of complete medium supplemented with $10 \mu \mathrm{g} /$ $\mathrm{ml}$ insulin (Wako Pure Chemical Industries), $200 \mu \mathrm{M}$ indomethacin (Wako Pure Chemical Industries), $500 \mu \mathrm{M}$ isobutylmethylxanthine (Sigma-Aldrich), and $1 \mu \mathrm{M}$ dexamethasone. The medium was replaced twice a week.

Chondrogenic differentiation was performed according to the pellet culture method [51]. We used chondrogenic differentiation medium (CDM) consisting of High-glucose DMEM (Gibco) supplemented with $2 \mathrm{mML}$-glutamine (MP Biomedicals), $50 \mu \mathrm{g} / \mathrm{mL}$ ascorbic acid-2-phosphate, $100 \mathrm{nM}$ dexamethasone, $100 \mu \mathrm{g} / \mathrm{mL}$ sodium pyruvate, 10 $\mathrm{ng} / \mathrm{mL}$ human recombinant TGF- $\beta 1$ (Sigma-Aldrich), and $50 \mathrm{mg} / \mathrm{mL}$ ITS+Premix (Corning). The medium was replaced twice a week.

\section{Examination and evaluation of MSC characteristics}

For osteogenic differentiation, MSCs were cultured in $\mathrm{ODM}$ at $37^{\circ} \mathrm{C}$ for 6 weeks. The ODM was replaced twice a week. For adipogenic differentiation, MSCs were cultured in ODM at $37^{\circ} \mathrm{C}$ for 3 weeks. After culturing for 3 weeks, the medium was replaced to ADM, and MSCs were cultured for an additional 3 weeks. As a control, MSCs were continuously cultured in ODM for 6 weeks.

For the calcium ( $\mathrm{Ca}$ ) production assay, MSCs were seeded in 6-well plates at a density of $1 \times 10^{5}$ cells/well and cultured in ODM or complete medium as negative control at $37^{\circ} \mathrm{C}$. After 4 and 6 weeks, Ca levels were evaluated using ESPA Ca (Nipro, Osaka, Japan).

For $\mathrm{Ca}$ staining assay, MSCs were seeded in 6-well plates at a density of $1 \times 10^{5}$ cells/well and cultured in ODM or complete medium at $37^{\circ} \mathrm{C}$. After 6 weeks, MSCs were stained with $1.3 \%$ alizarin red S solution for $2 \mathrm{~min}$ at room temperature. The cells were washed twice with phosphate-buffered saline (PBS), fixed with 100\% ethanol, washed twice with distilled water to remove staining solution, and then the plate was allowed to dry.

For lipid staining with oil red $\mathrm{O}$ solution, Oil red $\mathrm{O}$ staining was performed after adipogenic differentiation. The cells were washed twice with PBS, fixed with $10 \%$ formalin, washed once with distilled water and 60\% isopropanol, and then stained by Oil red $\mathrm{O}$ solution for $20 \mathrm{~min}$.

The chondrogenic differentiation potency was evaluated after 3 weeks culture in CDM. The cell pellet was washed twice with PBS and fixed with $4 \%$ formaldehyde overnight at $4{ }^{\circ} \mathrm{C}$. After paraffin embedding, the sample was cut into $5 \mu \mathrm{m}$ sections and stained with toluidine blue (Wako Pure Chemical Industries).

Isolation of total RNA and cDNA library preparation for RNA-sequencing (RNA-seq)

For RNA-seqencing, ilium-derived MSCs (I-MSCs), maxilla-derived MSCs (Mx-MSCs), and mandible-derived
MSCs (Md-MSCs) were seeded in $100 \mathrm{~mm}$ dishes at a density of $5 \times 10^{5}$ cells/dish and cultured in complete medium for 3 days. Total RNA was isolated using the RiboPure RNA Purification Kit (Thermo Fisher Scientific). When the RIN (RNA integrity number) score was $>9$, these RNA were used for RNA-seq. Strand-specific RNA libraries were obtained by the Dynabeads mRNA DIRECT Micro Purification Kit and the Ion Total RNA-Seq Kit v2.0 (Thermo Fisher Scientific). Each of RNA-seq template was prepared using the Ion PI Hi-Q OT2 200 Kit, the Ion OneTouch 2, and Ion OneTouch ES systems (Thermo Fisher Scientific). We performed RNA-seq using Ion Proton sequencer with Ion PI Hi-Q Sequencing 200 Kit (Thermo Fisher Scientific).

\section{Statistical and bioinformatics analysis}

Adaptor sequences of fastq file were removed by Cutadapt (v. 1.10), and low-quality bases of fastq file were trimmed by Trimmomatic (v. 0.35). Sequencing reads were aligned to the human reference genome (hg19) by Bowtie2 (v. 2.2.6) and Tophat 2 (v. 2.1.0) software [52]. We have performed Tophat2-Cufflinks (v. 2.2.1) packages pipeline to normalize uniquely mapped reads as fragments per kilobase of exon per million mapped fragments (FPKM) [53]. To detect differentially expressed genes (DEGs) between two groups, we used Cuffdiff that calculates a fold change for every gene, a $p$-value, and the false discovery rate with the Benjamini-Hochberg correction ( $q$-value) in the Cufflinks packages. DEGs were defined when the $q$-value $<0.05$ and the fold change of FPKM was $\geq 2.0$. The hg19 reference and the Refseq annotation were obtained from the UCSC Genome Browser (https://genome.ucsc.edu/). Enriched Gene Ontology (GO) terms were analyzed by the Database for Annotation, Visualization and Integrated Discovery (DAVID; https://david.ncifcrf.gov/) with the annotation dataset of GO biological process. Specific GO terms were gathered from the NCBI database (ftp://ftp.ncbi.nlm.nih. gov/gene/DATA/). Most of plots and graphs of RNA-seq analysis were visualized by ggplot 2 and other $\mathrm{R}$ packages. Clustering analysis was performed by the function hclust of $\mathrm{R}$ packages. All fastq file have been deposited in the DNA Data Bank of Japan (DDBJ) Sequence Read Archive under accession numbers DRA006607-006615. In the statistical analyses for $\mathrm{Ca}$ content assay, all of the values are reported as the mean \pm standard deviation (SD). Tukey's HSD test was performed for comparing differences between multiple groups. Differences were considered significant at $p<0.05$.

\section{Supplementary information}

Supplementary information accompanies this paper at https://doi.org/10. 1186/s12864-020-06825-2.

Additional file 1: Figure S1. Osteogenic and adipogenic differentiation potential of all MSC samples. Figure S2. Gene expression profile of all 
HOX genes in I-MSCS, Mx-MSCs, and Md-MSCs. Figure S3. Distinct gene expression patterns between Mfr-MSCs and other cells.

Additional file 2: Table S1. The information about the subjects.

\section{Abbreviations}

MSCs: Multipotent mesenchymal stromal cells; I-MSCs: Ilium-derived MSCs; Mx-MSCs: Maxilla-derived MSCs; Md-MSCs: Mandible-derived MSCs; ODM: Osteogenic differentiation medium; OD-MSCs: BM-MSCs cultured in ODM; PDL-MSCs: Periodontal ligament-derived MSCs; ESCs: Embryonic stem cells; ES-MSCs: ESC-derived MSCs; Mfr-MSCs: Maxillofacial region-derived MSCs; RNA-seq: RNA-sequencing; FPKM: Fragments per kilobase of exon per million mapped fragments; MФ: Macrophage; U-DEGs: Up-regulated DEGs in I-MSCs compared with Mx- and Md-MSCs; D-DEGs: Down-regulated DEGs in I-MSCs compared with Mx- and Md-MSCs

\section{Acknowledgments}

The super-computing resource was provided by the Human Genome Center, the Institute of Medical Science, and the University of Tokyo (http://sc.hgc.jp/ shirokane.html). We thank Sarah Williams, Ph.D., from Edanz Group (www. edanzediting.com) for editing a draft of this manuscript. The abstract has been presented recently on https://papers.ssrn.com/sol3/papers.cfm?abstract_id=3408026

\section{Authors' contributions}

SO, YY, and TI designed and conceived the project. SO and SJP analyzed the RNA-seq data. YY, TS, and YS designed and carried out in vitro experiments, and analyzed the data. SO, YY, and TI wrote the manuscript. SS, MU, AT, KN1, and KN2 contributed to data processing, discussions and advice and reviewed the manuscript. All authors read and approved the final manuscript.

\section{Funding}

This study was supported by the Japan Agency for Medical Research and Development (Grant number 17be0104010h0002) and the Japan Society for the Promotion of Science (KAKENHI Grant Number 17 K17219 and 19 K19056). The funders had no role in study design, data collection and analysis, decision to publish, or preparation of the manuscript.

\section{Availability of data and materials}

RNA-seq data generated and analyzed in this study have been deposited in the DNA Data Bank of Japan (DDBJ) Sequence Read Archive under accession numbers DRA006607-006615 (https://ddbj.nig.ac.jp/DRASearch/study?acc= DRP005861). The other data for subsequent RNA-seq were obtained from the National Center for Biotechnology Information (NCBI) Sequence Read Archive (SRA) database with the following accession numbers SRP055967 (https://trace.ncbi.nlm.nih.gov/Traces/sra/?study=SRP055967). We used human genome assembly GRCh37 (hg19), downloaded from the UCSC genome browser (http://hgdownload.cse.ucsc.edu/downloads.html\#human), and the Refseq annotation files were obtained from NCBI (https://ftp.ncbi.nlm.nih. gov/gene/DATA/). All scripts and data are available from the corresponding author on reasonable requests.

\section{Ethics approval and consent to participate}

The tissue collection process, cell culture, and RNA isolation were conducted according to the principles expressed in the Declaration of Helsinki and approved by the Institutional Review of Board Involving Human Subjects research at Kitasato University (approval number: B12-53). RNA-seq process and accessing the RNA-seq data in this study was approved by the Research Ethics Committee at Tokyo Women's Medical University (approval number: 4155). Written informed consent for the donation of their bone tissues and their subsequent samples used in this study was obtained from all patients prior to surgery. In the case of patients younger than 16 years old, both the patients and their parents (or legal guardians) provided written informed consent to participate in this study.

\section{Consent for publication}

Not applicable.

\section{Competing interests}

The authors declare that they have no competing interests.

\section{Author details}

'Division of Periodontology, Department of Oral Function, Kyushu Dental University, 2-6-1, Manazuru, Kokurakita-ku, Kitakyushu City, Fukuoka 803-8580, Japan. ${ }^{2}$ Department of Plastic and Aesthetic Surgery, Kitasato University School of Medicine, 1-15-1 Kitasato, Minami, Sagamihara, Kanagawa 252-0375, Japan. ${ }^{3}$ Human Genome Center, The Institute of Medical Science, The University of Tokyo, 4-6-1 Shirokanedai, Minato-ku, Tokyo 108-8639, Japan. ${ }^{4}$ Institute of Advanced Biomedical Engineering and Science, Tokyo Women's Medical University, 8-1 Kawada-cho, Shinjuku-ku, Tokyo 162-8666, Japan. ${ }^{5}$ Department of Periodontology, Graduate School of Medical and Dental Sciences, Tokyo Medical and Dental University, 1-5-45 Yushima, Bunkyo-ku, Tokyo 113-8510, Japan.

Received: 20 February 2020 Accepted: 15 June 2020

Published online: 22 June 2020

\section{References}

1. Prockop DJ. Marrow stromal cells as stem cells for nonhematopoietic tissues. Science. 1997;276(5309):71-4.

2. Pittenger MF, Mackay AM, Beck SC, Jaiswal RK, Douglas R, Mosca JD, Moorman MA, Simonetti DW, Craig S, Marshak DR. Multilineage potential of adult human mesenchymal stem cells. Science. 1999;284(5411):143-7.

3. Zuk PA, Zhu M, Ashjian P, De Ugarte DA, Huang Jl, Mizuno H, Alfonso ZC, Fraser JK, Benhaim P, Hedrick MH. Human adipose tissue is a source of multipotent stem cells. Mol Biol Cell. 2002;13(12):4279-95.

4. De Bari C, Dell'Accio F, Vanlauwe J, Eyckmans J, Khan IM, Archer CW, Jones EA, McGonagle D, Mitsiadis TA, Pitzalis C, et al. Mesenchymal multipotency of adult human periosteal cells demonstrated by single-cell lineage analysis. Arthritis Rheum. 2006;54(4):1209-21.

5. Trubiani O, Orsini G, Zini N, Di lorio D, Piccirilli M, Piattelli A, Caputi S. Regenerative potential of human periodontal ligament derived stem cells on three-dimensional biomaterials: a morphological report. J Biomed Mater Res A. 2008;87(4):986-93.

6. Onizuka S, Iwata T, Park SJ, Nakai K, Yamato M, Okano T, Izumi Y. ZBTB16 as a downstream target gene of Osterix regulates Osteoblastogenesis of human multipotent Mesenchymal stromal cells. J Cell Biochem. 2016; 117(10):2423-34.

7. Caplan Al, Correa D. The MSC: an injury drugstore. Cell Stem Cell. 2011;9(1):11-5.

8. Short BJ, Brouard N, Simmons PJ. Prospective isolation of mesenchymal stem cells from mouse compact bone. Methods Mol Biol. 2009;259-68.

9. Yamachika E, Tsujigiwa H, Matsubara M, Hirata Y, Kita K, Takabatake K, Mizukawa N, Kaneda Y, Nagatsuka H, lida S. Basic fibroblast growth factor supports expansion of mouse compact bone-derived mesenchymal stem cells (MSCs) and regeneration of bone from MSC in vivo. J Mol Histol. 2012; 43(2):223-33.

10. Nk M, Cy T, U B, Cll C, Eh W, Is P, T S. Investigating cell surface markers and differentiation potential of compact bone-derived Mesenchymal stem cells. Int J Stem Cell Res Transplant. 2015;3:91-5.

11. García-Gareta E, Coathup MJ, Blunn GW. Osteoinduction of bone grafting materials for bone repair and regeneration. Bone. 2015;81:112-21.

12. Sakkas A, Wilde F, Heufelder M, Winter K, Schramm A. Autogenous bone grafts in oral implantology —is it still a "gold standard"? A consecutive review of 279 patients with 456 clinical procedures. Int J Implant Dent. 2017;3(1):23.

13. Eufinger $H$, Leppänen $H$. lliac crest donor site morbidity following open and closed methods of bone harvest for alveolar cleft osteoplasty. J Craniomaxillofac Surg. 2000;28(1):31-8.

14. Boyne PJ. Secondary bone grafting of residual alveolar and palatal clefts. J Oral Surg. 1972;30:87-92.

15. Bajaj AK, Wongworawat AA, Punjabi A. Management of alveolar clefts. J Craniofac Surg. 2003;14(6):840-6.

16. Swan MC, Goodacre TE. Morbidity at the iliac crest donor site following bone grafting of the cleft alveolus. Br J Oral Maxillofac Surg. 2006;44(2):129-33.

17. Kinoshita $Y$, Maeda H. Recent developments of functional scaffolds for craniomaxillofacial bone tissue engineering applications. Sci World J. 2013; 2013:863157.

18. Dickinson BP, Ashley RK, Wasson KL, O'Hara C, Gabbay J, Heller JB, Bradley JP. Reduced morbidity and improved healing with bone morphogenic protein-2 in older patients with alveolar cleft defects. Plast Reconstr Surg. 2008;121(1):209-17. 
19. Nussenbaum B, Krebsbach PH. The role of gene therapy for craniofacial and dental tissue engineering. Adv Drug Deliv Rev. 2006;58(4):577-91.

20. Chang SC, Chuang H, Chen YR, Yang LC, Chen JK, Mardini S, Chung HY, Lu YL, Ma WC, Lou J. Cranial repair using BMP-2 gene engineered bone marrow stromal cells. J Surg Res. 2004;119(1):85-91.

21. Krebsbach PH, Mankani MH, Satomura K, Kuznetsov SA, Robey PG. Repair of craniotomy defects using bone marrow stromal cells. Transplantation. 1998; 66(10):1272-8

22. Mankani MH, Kuznetsov SA, Wolfe RM, Marshall GW, Robey PG. In vivo bone formation by human bone marrow stromal cells: reconstruction of the mouse calvarium and mandible. Stem Cells. 2006;24(9):2140-9.

23. Gimbel M, Ashley RK, Sisodia M, Gabbay JS, Wasson KL, Heller J, Wilson L, Kawamoto HK, Bradley JP. Repair of alveolar cleft defects: reduced morbidity with bone marrow stem cells in a resorbable matrix. J Craniofac Surg. 2007; 18(4):895-901.

24. Noden DM. Patterns and organization of craniofacial skeletogenic and myogenic mesenchyme: a perspective. Prog Clin Biol Res. 1982;101:167-203.

25. Couly GF, Coltey PM, Le Douarin NM. The triple origin of skull in higher vertebrates: a study in quail-chick chimeras. Development. 1993;117(2): 409-29.

26. Hass R, Kasper C, Böhm S, Jacobs R. Different populations and sources of human mesenchymal stem cells (MSC): a comparison of adult and neonatal tissue-derived MSC. Cell Commun Signal. 2011;9(1):12.

27. Wagner W, Wein F, Seckinger A, Frankhauser M, Wirkner U, Krause U, Blake J, Schwager C, Eckstein $V$, Ansorge W, et al. Comparative characteristics of mesenchymal stem cells from human bone marrow, adipose tissue, and umbilical cord blood. Exp Hematol. 2005;33(11):1402-16.

28. Leucht P, Kim JB, Amasha R, James AW, Girod S, Helms JA. Embryonic origin and Hox status determine progenitor cell fate during adult bone regeneration. Development. 2008;135(17):2845-54.

29. Matsubara T, Suardita K, Ishii M, Sugiyama M, Igarashi A, Oda R, Nishimura M, Saito M, Nakagawa K, Yamanaka K, et al. Alveolar bone marrow as a cell source for regenerative medicine: differences between alveolar and iliac bone marrow stromal cells. J Bone Miner Res. 2005;20(3):399-409.

30. Bronner ME, LeDouarin NM. Development and evolution of the neural crest: an overview. Dev Biol. 2012;366(1):2-9.

31. Chai Y, Maxson RE Jr. Recent advances in craniofacial morphogenesis. Dev Dyn. 2006;235(9):2353-75.

32. Oka K, Oka S, Hosokawa R, Bringas P Jr, Brockhoff HC, Nonaka K, Chai Y. TGF-beta mediated Dlx5 signaling plays a crucial role in osteochondroprogenitor cell lineage determination during mandible development. Dev Biol. 2008;321(2):303-9.

33. Matsuo A, Yamazaki Y, Takase C, Aoyagi K, Uchinuma E. Osteogenic potential of cryopreserved human bone marrow-derived mesenchymal stem cells cultured with autologous serum. J Craniofac Surg. 2008;19(3): 693-700.

34. Chang HY, Chi JT, Dudoit S, Bondre C, van de Rijn M, Botstein D, Brown PO. Diversity, topographic differentiation, and positional memory in human fibroblasts. Proc Natl Acad Sci U S A. 2002;99(20):12877-82.

35. Rinn JL, Bondre C, Gladstone HB, Brown PO, Chang HY. Anatomic demarcation by positional variation in fibroblast gene expression programs. PLoS Genet. 2006;2(7):e119.

36. Wang KC, Helms JA, Chang HY. Regeneration, repair and remembering identity: the three Rs of Hox gene expression. Trends Cell Biol. 2009;19(6): 268-75

37. Iwata T, Yamato M, Zhang Z, Mukobata S, Washio K, Ando T, Feijen J, Okano T, Ishikawa I. Validation of human periodontal ligament-derived cells as a reliable source for cytotherapeutic use. J Clin Periodontol. 2010;37(12):1088-99.

38. Satokata I, Maas R. Msx1 deficient mice exhibit cleft palate and abnormalities of craniofacial and tooth development. Nat Genet. 1994;6(4):348.

39. Alappat S, Zhang ZY, Chen YP. Msx homeobox gene family and craniofacial development. Cell Res. 2003;13(6):429.

40. Vastardis H, Karimbux N, Guthua SW, Seidman J, Seidman CE. A human MSX1 homeodomain missense mutation causes selective tooth agenesis. Nat Genet. 1996;13(4):417.

41. van den Boogaard MJ, Dorland M, Beemer FA, van Amstel HK. MSX1 mutation is associated with orofacial clefting and tooth agenesis in humans. Nat Genet. 2000;24(4):342-3.
42. Zhao Y, Guo Y-J, Tomac AC, Taylor NR, Grinberg A, Lee EJ, Huang S, Westphal $\mathrm{H}$. Isolated cleft palate in mice with a targeted mutation of the LIM homeobox gene Ihx8. Proc Natl Acad Sci. 1999;96(26):15002-6.

43. Redon R, Baujat G, Sanlaville D, Le Merrer M, Vekemans M, Munnich A, Carter NP, Cormier-Daire V, Colleaux L. Interstitial 9q22.3 microdeletion: clinical and molecular characterisation of a newly recognised overgrowth syndrome. Eur J Hum Genet. 2006;14(6):759-67.

44. Guo S, Zhang Y, Zhou T, Wang D, Weng Y, Chen Q, Ma J, Li YP, Wang L. GATA4 as a novel regulator involved in the development of the neural crest and craniofacial skeleton via Barx1. Cell Death Differ. 2018;25(11):1996-2009.

45. Balling R, Mutter G, Gruss P, Kessel M. Craniofacial abnormalities induced by ectopic expression of the homeobox gene Hox-1.1 in transgenic mice. Cell. 1989;58(2):337-47.

46. McLain K, Schreiner C, Yager KL, Stock JL, Potter SS. Ectopic expression of Hox-2.3 induces craniofacial and skeletal malformations in transgenic mice. Mech Dev. 1992;39(1-2):3-16.

47. Dominici M, Le Blanc K, Mueller I, Slaper-Cortenbach I, Marini F, Krause D, Deans R, Keating A, Prockop D, Horwitz E. Minimal criteria for defining multipotent mesenchymal stromal cells. The International Society for Cellular Therapy position statement. Cytotherapy. 2006;8(4):315-7.

48. Lotfy A, Salama M, Zahran F, Jones E, Badawy A, Sobh M. Characterization of mesenchymal stem cells derived from rat bone marrow and adipose tissue: a comparative study. Int J Stem Cells. 2014;7(2):135-42

49. Peng L, Jia Z, Yin X, Zhang X, Liu Y, Chen P, Ma K, Zhou C. Comparative analysis of mesenchymal stem cells from bone marrow, cartilage, and adipose tissue. Stem Cells Dev. 2008;17(4):761-73.

50. Tsumanuma Y, Iwata T, Washio K, Yoshida T, Yamada A, Takagi R, Ohno T, Lin K, Yamato M, Ishikawa I. Comparison of different tissue-derived stem cell sheets for periodontal regeneration in a canine 1-wall defect model. Biomaterials. 2011;32(25):5819-25.

51. Lee OK, Kuo TK, Chen WM, Lee KD, Hsieh SL, Chen TH. Isolation of multipotent mesenchymal stem cells from umbilical cord blood. Blood. 2004;103(5):1669-75.

52. Trapnell C, Pachter L, Salzberg SL. TopHat: discovering splice junctions with RNA-Seq. Bioinformatics. 2009;25(9):1105-11.

53. Trapnell C, Roberts A, Goff L, Pertea G, Kim D, Kelley DR, Pimentel H, Salzberg SL, Rinn JL, Pachter L. Differential gene and transcript expression analysis of RNA-seq experiments with TopHat and cufflinks. Nat Protoc. 2012;7(3):562-78.

\section{Publisher's Note}

Springer Nature remains neutral with regard to jurisdictional claims in published maps and institutional affiliations.

Ready to submit your research? Choose BMC and benefit from:

- fast, convenient online submission

- thorough peer review by experienced researchers in your field

- rapid publication on acceptance

- support for research data, including large and complex data types

- gold Open Access which fosters wider collaboration and increased citations

- maximum visibility for your research: over $100 \mathrm{M}$ website views per year

At BMC, research is always in progress.

Learn more biomedcentral.com/submissions 